\title{
PROMOÇÃO HUMANA PARA O AUTOCUIDADO EM SAÚDE NA FAMÍLIA
}

\author{
HUMAN PROMOTION FOR SELFCARE IN HEALTH IN THE FAMILY
}

PROMOCIÓN HUMANA PARA AUTOCUIDADO EN SALUD EN LA FAMILIA

\author{
Fátima Luna Pinheiro Landim* \\ Maria Geovana Câmara Opaleye** \\ Zulene Maria de Vasconcelos Varela***
}

\begin{abstract}
RESUMO: Descreve-se experiência de observação participante e intervenção de enfermagem com famílias pobres a partir do diagnóstico sócio-sanitário e da identificação de padrão de comportamento em saúde. A população é constituída de 400 famílias. O bjetivos: caracterizar padrões de comportamento no cotidiano da sobrevivência em saúde; descrever ações de enfermagem para promoção de habilidades no autocuidado com a saúde. A amostra contemplou 18 famílias selecionadas por processo natural considerando-se o engajamento voluntário de pessoas representantes das famílias nas atividades promovidas. 0 estudo desenvolveu-se em duas fases. A primeira fase caracterizou-se por visitas domiciliares e estabelecimento da rede social de apoio e do perfil de saúde das famílias. Na segunda fase deu-se a realização de 04 oficinas e a instalação de horta medicinal. Constituíram-se espaço para satisfação de necessidades psico-sociais como as de produzir e criar, promoção da auto-estima, ampliação das possibilidades de geração de renda familiar e de ensino-aprendizagem em saúde-doença-cidadania.
\end{abstract}

PALAVRAS CHAVE: S aúde da família; Desenvolvimento da comunidade; Autocuidado.

\section{INTRODUÇÃO}

\section{O PROBLEMA DA MISÉRIA E EXCLUSÃO SOCIAL}

Dois terços da humanidade estão representados por pessoas pobres ou miseráveis. Segundo dados evidenciados pelo Relatório do Desenvolvimento Humano referente ao ano de 1998, cerca 100 de milhões de pessoas em todo o mundo têm rendimentos considerados abaixo do nível de pobreza, mais de 37 milhões estão desempregadas, e 100 milhões de pessoas não têm sequer uma casa para abrigar-se com segurança (Araújo, 1999).

No que tange à particularidade da população brasileira, Mamede (1995) escreve que 32 milhões de pessoas vivem em situação que praticamente as exclui do processo social e modelo de desenvolvimento individual/coletivo. Nesse contexto a ausência de políticas definitivas de proteção à família configura-se no maior dos atentados contra a nossa sociedade.

S egundo R ibeiro (1999), 32\% das 15 milhões de famílias com pelo menos uma criança entre 0 e 6 anos de idade no Brasil vivem com renda mensal de meio salário mínimo. No Nordeste, essa proporção sobe para $55 \%$, e no Ceará a proporção de famílias com a mesma renda é de $65 \%$. Para essas famílias a miséria ultrapassa os limites da pobreza econômica, atingindo a identidade pessoal, impossibilitando a satisfação de necessidades fundamentais e responsabilizando-se pelo rompimento de muitos outros vínculos.

A R egião Nordeste também bate recordes quanto ao número de famílias vivendo em situações precárias, ou residindo em moradias inadequadas. Estima-se que das 5,6 milhões de moradias correspondentes ao déficit habitacional que essa região concentra, 150 mil são só na Capital do Ceará; uma realidade que afeta $36 \%$ de toda sua população (Oliveira, 1999). O caso agrava-se quando se constatam os altos índices de desemprego

\footnotetext{
* Doutoranda em enfermagem da Faculdade de Farmácia, Odontologia e Enfermagem-UFC. Bolsista da CAPES.

** Enfermeira de Saúde Pública da Prefeitura Municipal de Fortaleza.

*** Professora titular, UFA/Membro do Colegiado de Pós-graduação - Depto. de Enfermagem-FFOE/UFC.
} 
entre os chefes de família dessa mesma população. Em Fortaleza, o número conhecido de desempregados subiu de 105.072 em fevereiro de 1999, para 113.136 em março do mesmo ano. A reinserção desse contingente no mercado de trabalho é, segundo Stéfano (1999), complexa, enquanto variável, e vem determinando tendências. Entre as pessoas na faixa etária de 30 a 39 anos a taxa de recolocação é de apenas $26,61 \%$, dentre aqueles que mantêm um cadastro de desemprego. Para a faixa etária de 40 a 49 anos essa taxa cai para 8,47\%.

0 modelo de desenvolvimento sócio-econômico vigente vem, assim, concorrendo para a discriminação da pessoa a partir de sua exclusão dos espaços sociais. As condições criadas pelo estabelecimento do quadro de desemprego e miséria eliminam a dignidade, além de comprometer a capacidade de enfrentamento das adversidades sócio-ambientais e de processos mórbidos na família. É que, dada a fragilidade em que se encontram, as pessoas não conseguem apresentar sequer competência para manipular eficazmente mecanismos básicos que possibilitem o exercício e a efetivação da cidadania - saneamento básico, acesso a atendimento médico-hospitalar, educação, moradia, para citar alguns.

Surgem, pois, as favelas. Estas, fruto de dramas sociais como o desemprego e a miséria, mostram-se como aglomerados "sub-humanos" que se mantêm alimentados, principalmente, pela falta de renda familiar suficiente para pagar o aluguel sequer de uma casa de dois cômodos. Com elas (as favelas) nasce também um modelo particular de estruturação familiar; nesse modelo crescem e se reproduzem relações permeadas por desigualdades, disputas por espaço, privações materiais e afetivas, dramas pessoais e conjugais, episódios de violência (Varela, 1992).

A realidade da família "favelada" é a realidade imposta pelas dificuldades econômicas e de redefinição dos padrões de convivência. Não obedece a uma forma única e específica de estruturação, configurando-se de acordo com o espaço conquistado e a maneira que cada um concebe o seu lugar no mundo social e de relações familiares.

Nessa nova realidade, família, muitas vezes, tem representação na figura exclusiva da mulher que luta pela sobrevivência pessoal e de seus dependentes. Segundo o ultimo levantamento realizado pelo IBGE, até 1996 o número de famílias chefiadas por mulheres na região Nordeste era de $28,3 \%$. Considerando essa realidade, Araújo (1999) alerta para um agravante dessa situação no Estado do Ceará; o de que $45 \%$ de todas as famílias chefiadas por mulher vive sob um patamar de renda que não supera meio salário mínimo por pessoa.

A exposição repetitiva dessa mulher a situações de adversidade imposta pela privação vai fragilizandoa, o que pode permitir a manifestação de sintomas do processo defensivo (inibição e inércia), seguindo-se a parada no processo de atualização da pessoa (Saint-Arnaud, 1979). Ou seja, na medida em que fragiliza, distancia a pessoa da vivência dos valores humanos, da busca do belo, da verdade, do bem comum características inerentes ao ser humano em processo de desenvolvimento humano.

Essa fragilização e sucessiva queda da auto-estima pode ter diferentes manifestações. Há mulheres que manifestam mais fortemente os aspectos subjetivos da depressão, outras somatizam apresentando sintomas físicos e, há, ainda, aquelas que diante dos problemas renovam suas forças e conseguem sobreviver. Considerando estas últimas, ressalta-se F rankl (1996) que fundamenta a logoterapia (terapia centrada na busca de sentido) na certeza de que a vida, mesmo em circunstâncias trágicas, tem sentido. Assim, a própria agressão contextual pode levar essas mulheres e suas famílias a descobrirem mecanismos particulares que objetiva a preservação da vida.

Corrobora com o pensamento de Frankl (1996), Barreto (1995) quando defende que uma mesma estrutura social que reproduz relações caracterizadas por conflitos, violência, desigualdades, injustiça e individualismo, oferece às pessoas aprendizado novo de como resolver seus problemas e suprir suas necessidades. Assim, no decorrer de suas trajetórias de vida, as mulheres vão elegendo prioridades em termos de sobrevivência, e se observadas com atenção as suas práticas (mecanismos de sobrevivência), perceber-se-á que se desenvolvem e se legitimam porque as auxiliam a saciarem a fome da família, encontrarem abrigo e segurança, cuidarem dos problemas de saúde emergentes e visíveis. Todavia, o que se observa são famílias que buscam superar as adversidades construindo um estilo de vida que, cada vez mais, as identifica como excluídos sociais.

Considerando a tendência à atualização do ser humano (Saint-Arnaud, 1979) e considerando a possibilidade de reverter a situação de aparente inércia em que vivem segmentos populacionais excluídos da dinâmica social - e, portanto, excluídos de recursos acessíveis àqueles que se sentem saudáveis, são escolarizados, estão qualificados para o trabalho e estão inseridos em grupos de referência - questiona-se: como 
se comportarão famílias pobres às quais se oferecerão estímulos diversificados para o auto-cuidado em saúde a partir da mobilização de recursos disponíveis em seu meio? A partir desse questionamento estabeleceram-se os seguintes objetivos de estudo:

GERAL

Contribuir para que as famílias investigadas estabeleçam respostas satisfatórias na resolução de problemas básicos de saúde.

\section{ESPECÍFICOS}

- Caracterizar os padrões de comportamento de famílias pobres no cotidiano da sobrevivência em saúde.

- Descrever ações de enfermagem que se voltam para promover e potencializar habilidades naturais da família no autocuidado com a saúde.

\section{ABORDAGEM METODOLÓGICA}

\section{TIPO DE ESTUDO E CENÁRIO DE INVESTIGAÇÃO}

Trata-se esse estudo de Relato de Experiência, originado das atividades desenvolvidas pelas autoras junto a famílias pobres inserida no programa "P ró-moradia" - uma proposta social de implantação de um Conjunto Habitacional na zona Oeste da cidade de Fortaleza, Ceará. Tal proposta é desenvolvida pela P refeitura Municipal de F ortaleza(CE), em parceria com lideranças comunitárias e Caixa E conômica Federal do Ceará. Cerca de 400 famílias habitavam, em condição de aglomerado, barracos no terreno destinado às obras de construção do conjunto até a data de encerramento das atividades de campo. Essa condição de morar em barracos originou para essas famílias uma forma muito particular de tratamento. Eram referidas pelas lideranças, e referiam-se umas as outras como "barraqueiras"; eram, e são elas, as "famílias barraqueiras".

\section{POPULAÇÃO E AMOSTRA}

Constituiu população do estudo as famílias barraqueiras, tendo feito parte da amostra 18 destas famílias. A determinação da amostra deu-se por processo natural de seleção, considerando o engajamento voluntário de representantes das famílias nas atividades de implantação de uma Horta Medicinal Comunitária e nas 04 (quatro) oficinas desenvolvidas (oficina de redes, oficina de corte de cabelo, oficina de pintura em tecido e de transformação de sucata em utensílios domésticos ou peças de decoração).

\section{MÉTODOS, TÉCNICAS, INSTRUMENTOS E RECURSOS}

0 estudo desenvolveu-se em duas fases que se complementam. Inicialmente, realizou-se o diagnóstico sócio-sanitário das famílias. Tal levantamento foi favorecido pela possibilidade de consulta a documentos e registros mantidos por líderes comunitários. Os documentos acessados revelaram informações como o total de famílias habitando o terreno tomado como cenário de investigação, o número de pessoas por família, a idade dessas pessoas, o sexo do chefe de família por unidade habitacional, a renda familiar, o tipo de assistência recebida da liderança da associação, os serviços da rede de suporte sócio-sanitário que atendem à Comunidade, dentre outras. Durante as visitas domiciliares essas informações foram validadas e colhidas outras com importância para o que nos propusemos.

A visita domiciliar também funcionou como recurso inicial para se conhecer a estrutura e dinâmica das famílias em interação. Essa foi a oportunidade real de fazer-se conhecida e aceita por essas famílias, para então colher informações indispensáveis à elaboração de diagnóstico o mais próximo possível da realidade.

Da mesma forma foram levantadas as organizações e entidades atuantes na área da comunidade que 
servem de referência para essas famílias (grupos de encontros, associações, sociedades comunitárias, dentre outros); também as instituições que, presentes na comunidade, podem e vêm contribuindo de algum modo para com o acompanhamento e promoção de saúde e vida social dos indivíduos (escolas, postos de saúde, creches, postos policiais, templos, dentre outros).

Um exame físico e a anamnese das pessoas da família revelaram os problemas de saúde que mais se exacerbavam. J untamente com o levantamento da existência de outras queixas acerca de problemas de saúde na família, buscou-se descobrir o que é feito nessas circunstâncias, que serviços são procurados, que tipo de procedimentos são adotados e se esses procedimentos têm resolutividade em resposta às queixas. As respostas a essas perguntas possibilitaram a eleição de estratégias de resolução que mais se adequassem às necessidades das famílias.

Foram as estratégias postas em prática através da instalação de uma Horta Medicinal Comunitária e da realização de oficinas que visaram trazer conhecimento às famílias de como proceder para, utilizando-se dos recursos pessoais e comunitários, superar as dificuldades enfrentadas e suprir necessidades - imediatas e a longo prazo - de proteção e promoção da saúde. As oficinas realizadas tiveram, ainda, o propósito de servir como espaço para satisfação de necessidades como as de produzir e criar, promoção da auto-estima, ampliação das possibilidades de geração de renda familiar dentre outras.

A partir dessas atividades estabeleceu-se relação de confiança, criando-se condição para o ensinoaprendizagem, orientação em saúde-doença-cidadania, conversação e motivação para atividades em autopreservação da saúde.

Houve situações em que era exigido encaminhamento de um dos membros da família a serviço de saúde especializado. Nessas ocasiões, de posse de informações consistentes acerca das condições de vida e de saúdedoença daquelas famílias, o contato com unidade de saúde da área resultou em convencimento de seus coordenadores, gerando parceria que beneficiava as famílias barraqueiras com um dia da semana em que a unidade dedicava-se ao atendimento das pessoas encaminhadas pela equipe de enfermeiras pesquisadoras.

\section{PESSOAL ENVOLVIDO NAS ATIVIDADES}

Além das enfermeiras pesquisadoras, envolveram-se nas atividades de programação, execução das oficinas e acompanhamento das famílias através de palestras e visitas domiciliares, bolsistas de enfermagem da UFA; instrutoras voluntárias nas atividades práticas de confecção de redes, corte de cabelo, transformação de sucata em peças de decoração ou utensílio doméstico dentre outras.

Além das pessoas referidas, foram sendo contatados, ao longo do processo, lideranças comunitárias, donos de casas de espetáculo, profissionais liberais, grupos religiosos e outros segmentos da sociedade capazes de contribuir com apoio técnico, de consultoria ou através de doações que viabilizassem as oficinas e favorecem ao processo de interação com a comunidade.

\section{PRINCÍPIOS ÉTICOS E CIENTÍFICOS APLICADO A PESQUISA}

Durante todo o processo de investigação o pesquisador deve atentar para os princípios éticos e científicos que regem a pesquisa qualitativa, não os contrariando afim de garantir sua legitimidade e resguardar as pessoas que fizerem parte dela (Demo, 1992).

No que tange aos aspectos da ética na pesquisa, a Associação Americana de Antropologia estabeleceu princípios que devem ser conhecidos e observados quando o pesquisador trabalha considerando seres humanos (Spradley, 1980). Dentre eles destaca-se:

1. O pesquisador deverá fazer o que estiver ao seu alcance para proteger o bem-estar físico, social e psicológico do informante, assim como a sua privacidade.

2. Salvaguardar, a todo custo, os direitos e interesses dos informantes.

3. Comunicar-Ihes os objetivos, benefícios e riscos (se existirem) da pesquisa.

4. Guardar o direito do informante desistir de sua participação no estudo em qualquer uma de suas fases.

5. Não tirar proveito ou explorar as informações captadas para outros fins que não os estabelecidos nos 
objetivos de estudo.

6. Manter os registros, bem como o texto final do estudo realizado, à disposição dos informantes.

Quanto à obediência aos critérios científicos, destaca-se a opção feita pelo uso de máquina fotográfica para o registro das atividades de oficinas, bem como o de reconhecimento das condições dos barracos e da área em que eles estão assentados. Obrigamo-nos como pesquisadoras, desta feita, a obter consentimento prévio das famílias para realização das fotos e, após conclusão do estudo, apresentamos a elas para que validassem os critérios/pertinência das afirmações e utilização das fotos. A anuência da pessoa informante foi registrada em termo de consentimento, conforme R esolução 196/96 do Conselho Nacional de Saúde/Ministério da Saúde (Brasil, 1996).

\section{RESULTADOS}

\section{A COMUNIDADE DO ESTUDO:PERFIL SÓCIO-SANITÁRIO E DE SAÚDE DAS FAMÍLIAS BARRAQUEIRAS}

Do levantamento do perfil sócio-econômico das famílias barraqueiras constatou-se a inexistência de vínculo empregatício entre a maioria dos chefes de família. A renda mensal, proveniente quase que exclusivamente do mercado informal, situa-se entre zero (00) e dois (02) salários mínimos; sendo que a maioria dessas famílias $(40,01 \%)$ tem renda de até um (01) salário mínimo, enquanto 31,14\% das famílias é que consegue captar uma renda mensal de até dois salários, muitas vezes, contando com a capacidade de trabalho de mais de um membro da família que assumem muitas atividades ao mesmo tempo (vendedor ambulante e vigia noturno para os homens, lavadeira e passadeira de roupa para as mulheres são alguns exemplos). Destacaram-se, como preocupação para a equipe de pesquisadoras, os demais $22,85 \%$ das famílias que referiram não contar com renda alguma. Estas, descobriu-se com os freqüentes contatos, sobreviverem com ajuda de doações de grupos religiosos, ajuda da família, da liderança e de seus vizinhos. Identificou-se ainda que $80 \%$ dos chefes de famílias não concluíram o primeiro grau; $45 \%$ desses chefes de família são mulheres que situam-se na faixa etária de 30 a 50 anos; idade após a qual, segundo elas mesmas relatam, torna-se mais difícil encontrar um companheiro (Ceará, 1999).

Durante as visitas domiciliares previstas constatou-se o porque de as famílias residirem em situação considerada de risco pela Defesa Civil e demais segmentos sociais de apoio e proteção à vida e à saúde da população. Isso se deve a que habitam barracos constituídos de tábuas, caixotes, papelões, sacos plásticos e todo resto de material possível de ser aproveitado para esse fim. Estão os barracos construídos nas encostas de canais de esgoto e aterros sanitários, isentando seus moradores de conforto, segurança física, instalações hidráulicas e sanitárias.

Nesses barracos - muitos deles sem um piso que recubra a areia do chão batido - crianças, adultos e velhos se aglomeram em espaço único e contando com poucos metros quadrados. Esse espaço é, ainda, dividido com a humilde mobília.

É comum encontrar duas ou até mais famílias habitando o mesmo barraco que, quase sempre, não comporta a todos; ou quando comporta, faz-se em condições de extremo desconforto. A média de pessoas por família não é, assim, nunca inferior a cinco, sendo alto o número de crianças na faixa etária de 0-4 anos de idade.

Todo material descartado pela sociedade (papel, plástico, tábuas, papelão) e depositados nos "lixões", vai para a construção dos barracos; tapar um buraco, evitar uma goteira, construir um local de dormida, recuperar a porta. Também são nesses "lixões" que algumas das famílias encontram seu meio particular de sobreviver ao desemprego e exclusão social - que em muito é favorecido pela localização dos terrenos e condição de aglomerado. Ali o que é "catado" e não serve para compor o barraco é vendido por valores simbólicos em depósitos que negociam materiais recicláveis.

Não há, para essas famílias, lugar adequado para depositar água servida, lixo ou dejetos. Todo esse material é lançado a "céu aberto", em terrenos baldios ou em canais de esgoto localizados nas imediações. Tal situação favorece à proliferação de insetos e vetores de doenças relacionadas à ausência de saneamento básico, tais como baratas, moscas, mosquitos, roedores. Em verdade, insetos e ratos passaram a fazer parte do 
dia-a-dia das pessoas da comunidade que, embora temam essa presença, desconhecem a verdadeira dimensão de seus riscos. Nesse ambiente desprovido de condições mínimas que propiciem a manutenção do padrão adequado de higiene nos barracos, os brinquedos das crianças e mesmo outros utensílios sem utilidade prática diária, passam a constituir risco, podendo determinar aumento dos problemas de saúde na medida em que funcionam como abrigo de insetos e roedores, acumulam poeira e sujidade. Nessa realidade, também a alimentação, mesmo quando existente em quantidade suficiente, pode estar comprometida em sua qualidade, se consideradas as características de acondicionamento, preparo e utilização.

E $m$ algumas das pessoas não se viam roupas limpas, pés asseados, mãos lavadas, unhas ou cabelos cuidados. 0 olhar triste, a sensação de abandono, a força física espoliada dia a dia pela imposição de sofrimentos são fatores que vão desenhando o quadro de morbidez característico ao local. Segundo relatos durante as visitas, desde a criança contando com apenas alguns meses, até os mais idosos, eliminam vermes, em grande quantidade e espontaneamente, nas fezes e, em alguns casos, também por via oral através de vômitos.

Intimamente relacionados com a carência material e precárias condições de moradia, também as doenças infecciosas, o "bicho de pé", a pediculose, dermatites foram problemas facilmente identificados através da anamnese e realização de exame físico. Além desses, entre as crianças, destacam-se as doenças relacionadas com o aparelho gastrointestinal e respiratório. Os índices de desnutrição atestados foram altíssimos, principalmente entre os grupos mais susceptíveis: menores de cinco anos, gestantes e idosos.

Foram inúmeras as queixas referentes a má qualidade e a dificuldade de acesso aos serviços de saúde que funcionam como referência para a área de ocupação. Somadas a essas dificuldades, a desinformação e a ausência de recursos vai privando ainda mais essas famílias de usufruir o direito à saúde.

Constatou-se que, estando doente, a família tenta buscar ajuda mas depara-se com as barreiras físicas e estruturais características aos serviços de saúde da atualidade. Não conseguem ultrapassá-las. As unidades de saúde, de referência para a área, por sua vez, não conseguem responder satisfatoriamente à demanda e à complexidade dos problemas que emergem da comunidade. Nelas não há estrutura adequada para acomodar todos os pacientes, nem profissionais em número e em especialidade para prestar 0 atendimento. Se atendidos os pacientes, a assistência, muitas vezes, não se efetiva dada a falta de equipamento adequado, medicamentos e, principalmente, um sistema de referência e contra-referência atuante.

De mesma dimensão é o drama vivenciado por outras famílias que encontram limitações na própria carência de informações e na privação de estímulos intelectuais; o que dificulta, ainda mais, o reconhecimento da gravidade dos problemas enfrentados, adiando a procura por socorro adequado.

0 alto índice de desemprego entre os jovens e chefes de família foi evidenciado como a principal causa para as grandes dificuldades financeiras e de convivência enfrentadas por essas famílias. Dentre os possíveis fatores que concorrem para o fenômeno levantou-se: a ausência de formação escolar básica e a desqualificação de mão-de-obra.

Confirmou-se posteriormente, ser o desemprego, para a comunidade em evidência, uma variável de peso, tendo influência considerável no aumento da violência no lar contra mulheres e crianças, evasão escolar, e prevalência das morbidades (muitas delas relacionadas, diretamente, com desnutrição séria em crianças menores de 05 anos - conseqüência da ausência de alimentos ou da dieta hipoprotêica, hipocalórica, da ausência de água tratada e das precárias condições de saneamento básico).

O desemprego funciona, ainda, como justificativa para o abuso de bebida alcoólica, o tabagismo e a utilização de maconha, que passam a funcionar como "âncoras" sociais. Foi possível identificar famílias com portadores de tuberculose ativa, cuja causa do abandono da terapêutica reside nos fatores supracitados. Levantou-se, ainda, na comunidade relato de tentativa de suicídio por um chefe de família. Tal ocorrido reflete o desespero ocasionado pela associação de todos os fatores já referidos e que exacerbam o quadro de miséria e de abandono dessas famílias.

Também ficou constatado que as dificuldades para conseguir emprego aumentam entre os homens com 40 ou mais anos, idade após a qual passam a ser descartados da possibilidade de concorrer a qualquer vaga em muitas das empresas existentes.

0 desemprego dos maridos ou mesmo o abandono por parte destes, vem contribuindo para o aumento 
dos casos em que mães-de-família obrigam-se a trabalhar fora de casa e tentar garantir, assim, alimento para os filhos. Dada a ausência de formação mínima e à desqualificação de mão-de-obra dessas mulheres, a ocupação que ainda prevalece é a de empregada doméstica, sob condições de dedicação em tempo integral e com baixa remuneração. Enquanto a mãe trabalha, as crianças mais novas ficam ao encargo das mais velhas ou sob os "cuidados" do pai, quando este não vai embora. Como grande parte desses pais são alcoólatras e, muitas vezes, o vicio está associado com outras drogas como a maconha, evidencia-se, ainda, a iminência de risco a integridade física, moral e psicológica dessas crianças.

\section{AESTRATÉGIA DE OFICINAS E SUAREPERCUSSÃO}

Feito o reconhecimento da área e levantamento das principais necessidades em termos de cuidado com a saúde daquelas famílias, foram organizadas as oficinas apresentadas a seguir.

\section{Oficina de corte de cabelo}

Com essa oficina visou-se a geração de hábitos saudáveis, promoção da auto-estima, qualificação de mãode-obra para suprimento do orçamento doméstico.

$\mathrm{Na}$ oficina dava-se a aquisição de conhecimento e habilidades relacionadas com o corte e arrumação do cabelo, cuidados com a saúde e higiene do couro cabeludo e eram prestadas orientações básicas de como proceder para evitar e tratar a pediculose e infecções secundárias do couro cabeludo.

Essa oficina desenvolveu-se durante encontros previamente estabelecidos. 0 horário e duração dos encontros também foram acordados com as famílias e considerou a disponibilidade dos interessados em participar.

A instrutora foi pessoa habilitada que voluntariou-se para explicar e treinar as técnicas com o grupo. Os próprios participantes funcionaram como modelos voluntários para as técnicas de corte. Posteriormente, pessoas identificadas na comunidade ofereceram-se como voluntárias para que os aprendizes aplicassem as técnicas sob acompanhamento da instrutora. Assim, ao mesmo tempo em que estes aperfeiçoavam a habilidade de cortar cabelo, prestavam um serviço às demais famílias da comunidade.

A avaliação do significado desse processo para o desenvolvimento pessoal no auto-cuidado em saúde, baseia-se no índice de satisfação do grupo e na habilidade e conhecimento adquiridos e compartilhados. 0 depoimento dos participantes acerca do significado das atividades para a geração de hábitos saudáveis relacionados com o cuidado, com a aparência e a higiene pessoal e do grupo familiar foi outro critério de avaliação, e veio a validar a estratégia como tendo sido eficaz, respondendo ao propósito para o qual foi criada.

\section{Oficina de confecção de rede de dormir}

A grande importância das oficinas de confecção artesanal de redes para as famílias barraqueiras justificouse pela constatação de problemas respiratórios e de pele relacionados com as características da dormida.

Durante as visitas verificou-se que devido ao pouco espaço e a ausência de recursos materiais o simples ato de dormir à noite (o atendimento da necessidade básica de sono e repouso) tornava-se um desafio, além de ser incompatível com a dignidade humana. No barraco as pessoas da família dormiam em tábuas, papelões ou em colchões muito velhos e sujos.

A dificuldade de manutenção adequada das poucas redes existentes nos barracos denunciava a necessidade de atividades que resgatassem a prática de fabricação e conserto com fins de prolongar o tempo de vida útil destas redes.

Com a confecção de redes pretendeu-se alcançar objetivos de diferentes naturezas: satisfazer a necessidade de sono compatível com as demandas orgânicas, promover a dignidade humana e preencher a necessidade psico-social de produzir e criar.

Associada às instruções de confecção da rede artesanal foram oferecidas informações sobre os riscos a 
que se expõem crianças e adultos quando dormem muito próximos ao chão (em tábuas e papelões, por exemplo) ou quando têm suas redes, lençóis e colchões impregnados por sujidade e microorganismos (fungos, ácaros, pulgas, etc.). Da mesma forma, procedimentos caseiros para prevenção e tratamento das principais dermatoses, dentre aqueles já utilizados pelas famílias com comprovado valor terapêutico eram incentivados.

Todo o material para início das oficinas de confecção das redes vieram de doações de particulares. A instrutora é dona de casa e foi voluntária nas atividades de oficina.

Estimulou-se para que a experiência particular da instrutora com a confecção e venda do produto elaborado fosse compartilhada com os demais, funcionando, dentre outros aspectos, como um incentivo a mais para que as pessoas acreditassem na viabilidade da proposta, passando a repetir todo os procedimentos apreendidos, utilizando-se dos recursos disponíveis em casa.

Percebemos que o envolvimento com as atividades beneficiou o grupo, composto em quase sua totalidade de mulheres, tendo efeito terapêutico na medida em que a pessoa sai da rotina de casa, familiariza-se com os espaços sociais, deseja e ocupa um desses espaços. Por outro lado, a família está satisfeita pela possibilidade de complemento no orçamento familiar através do desenvolvimento da técnica aprendida.

Assim, ao termino das atividades, duas redes foram confeccionadas.

As pessoas que se destacaram na oficina foram encorajadas a formarem grupo para continuar trabalhando com a confecção de redes, agora como uma atividade voltada para geração de renda familiar.

Foram produzidas duas redes. Uma delas motivou a união do grupo para a realização de um bingo, tendo sido as cartelas vendidas pelo valor simbólico de 0,50 centavos às pessoas da própria comunidade; assim a rede ficou para quem necessitava dela, enquanto o valor apurado foi revertido em material para continuidade das oficinas. A segunda rede foi doada pelas enfermeiras pesquisadoras ao grupo de cinco mães de família que se formou a partir da oficina e que, seguindo o mesmo processo realizado com a primeira rede, reverteu esse objeto no capital necessário para a compra de material que possibilitou início de novas atividades. Todo o processo, a iniciar pela idéia de pessoas trabalhando juntas por um objetivo comum, passando pelo prazer de construir algo com as próprias mãos e finalmente chegando ao desfecho final - a transformação do produto elaborado em fonte de renda - funcionou como exemplo do quanto a ação pode ser simples, economicamente viável e de ritual importante no processo de interação grupal.

\section{Oficinas com sucata e pintura em tecido}

Com esta oficina, além do objetivo comum a todas as demais que era a de ampliação das possibilidades de geração de renda familiar, pretendeu-se promover a arte de criar beleza em casa.

Nessas oficinas jovens e adultos desenvolveram atividades utilizando-se de papel e outros materiais reciclados para elaboração de peças de decoração e utilidades domésticas. As atividades foram sendo diversificadas na medida em que havia solicitação do grupo para explorar habilidades de pintura em tecido, crochê, montagem de arranjo de flores dentre outras.

Essa proposta visou, ainda, despertar as famílias para a necessidade de iniciar em casa a coleta seletiva do lixo, aproveitando todo e qualquer material que possa ser reutilizável, principalmente o papel. Para além disto, as oficinas visam capacitar pessoas na utilização, em suas casas, de todo tipo de material reciclável para elaboração de peças de utilidade doméstica ou para comercialização.

Tiveram, assim, as oficinas o papel de despertar a criatividade levando a comunidade a perceber que a reciclagem pode ser uma atividade viável e lucrativa, além de promover comportamento mais saudável na relação com o meio ambiente.

As observações iniciais revelaram a grande resistência por parte das famílias em aceitar que um recipiente outrora destinado ao lixo pudesse vir a compor um artefato de uso em sua casa. Para muitas delas, esse seria um motivo de zombaria por parte da vizinhança. Todavia, ao término das atividades, constatouse que famílias passaram não só a fazer uso de artigos confeccionados a partir de elementos descartáveis, como também ensinavam ao seus vizinhos. Assim, garrafas plásticas de refrigerante, por exemplo, viraram recipientes seguros para manter talheres, cereais e biscoitos livres de umidade e do contato com insetos. Os jornais e revistas velhas transformavam-se em bonitas cestas e jarros para decoração da casa, que se tornava 
mais alegre e bonita.

Todo material produzido nas oficinas era vendido por quantia simbólica em pequenas exposições e feirinhas realizadas para a comunidade e que marcavam o encerramento das atividades com os grupos. 0 dinheiro arrecadado era revertido na compra de material para a continuidade das oficinas. Pessoas da comunidade que ganharam habilidade nas oficinas foram incentivadas a voluntariar-se, funcionando como instrutoras em oficinas subsequentes.

\section{SOBRE A HORTA MEDICINAL COMUNITÁRIA}

Verificou-se que quando doentes, muitas das famílias barraqueiras vão buscar ajuda nas velhas curandeiras e rezadeiras, nos chás e preparos de raízes e ervas para auxiliar no tratamento de enfermidades. Essa utilização de plantas para chás e outros preparados caseiros com fins terapêuticos fundamenta-se apenas no conhecimento empírico, conhecimento este recheado por superstições, crenças e tabus. Quase sempre são receitas passadas de geração a geração sem o devido cuidado na observância da fórmula ou da adequada relação planta-problema a ser trabalhado. Não há conhecimento, e portanto preocupação, quanto à toxidade de algumas dessas plantas e não se consideram as possíveis contra-indicações.

A realidade é que a utilização das plantas vem funcionando como uma opção para essas famílias, que não vêm conseguindo assistência nas unidades de serviço público de saúde ou não dispõem do dinheiro necessário ao tratamento medicamentoso.

Quando não é a própria família quem prepara seus chás e cozimentos, pessoas de referência na própria comunidade são procuradas para aquisição de produtos ("garrafadas") que são comercializados por preços acessíveis, se comparados aos farmacoterápicos. Constatou-se ser que a "indicação" para o uso desse preparo comercializado é sempre muito abrangente, mas raramente as pessoas podem ter a certeza de seus elementos constitutivos.

As plantas utilizadas são colhidas nos próprios quintais, solicitadas a vizinhos ou, muitas vezes, adquiridas em hortas particulares. Nessas condições, a contaminação ou não desse material é desconhecida e o manuseio duvidoso.

Foram considerando essas práticas das famílias investigadas, no que tange ao cuidado com a saúde, que se deu andamento à proposta de construção de uma Horta Medicinal Comunitária. Para viabilização da horta, o espaço físico foi cedido pela liderança. Esse fazia parte de uma área já contemplado em planta técnica como estando reservada ao "reflorestamento" e espaço de lazer para as famílias que viessem a habitar as unidades do conjunto em construção.

Parte do material utilizado para fazer o isolamento da área destinada à horta e a confecção dos canteiros foi adquirido através de doações de particulares que se envolveram com a causa (arame farpado, pregos, mangueiras e irrigadores, adubo orgânico dentre outros). 0 restante do material foi conseguido pelas próprias famílias barraqueiras, contando com os recursos naturais do terreno e as sobras de material desprezado pela empresa de construção encarregada das obras do conjunto habitacional (tijolos, barro vermelho, estacas).

Elaborou-se lista com o nome das ervas e plantas conhecidas e tradicionalmente utilizadas pelas famílias barraqueiras com fins "terapêuticos". As mudas dessas ervas e plantas foram doadas pelo Setor de Meio Ambiente da Secretaria Regional III. A atividade braçal de confecção da horta coube aos representantes das famílias barraqueiras; aqueles mais capacitados.

E $m$ retribuição aos esforços empreendidos nessas atividades foram distribuídas entre os participantes "cestas básicas", doadas por empresário da área de transportes coletivos.

E $\mathrm{m}$ todas as etapas de planejamento e implantação do que se preconizou como a Horta Medicinal Comunitária, buscou-se assessoria de profissionais agrônomos e enfermeira especialista em fitoterapia.

A horta medicinal comunitária, assim, surgiu para ser um espaço utilitário e educativo, que possibilitasse o esclarecimento das famílias acerca do uso adequado e oportuno das plantas que têm efeito comprovado e seguro em queixas específicas, evitando desta forma, os riscos a que elas estavam expostas quando usavam as plantas indevidamente.

Com auxílio técnico e de literatura especializada, o trabalho educativo visou, ainda, trazer informações 
que favorecessem o reconhecimento de plantas de uso popular em sua variedade e grau de toxicidade, bem como noções de higiene para o cultivo e manuseio dessas plantas.

Não se pretendeu com esse trabalho viabilizar ou não o emprego terapêutico de plantas. Todavia, 0 aspecto mais importante na implantação da proposta primava para que as várias etapas que a constituíram viessem a resultar na fixação de um espaço comunitário para o encontro das famílias e onde pudessem ir sempre que tivessem dúvidas ou necessitassem de esclarecimento sobre o uso adequado e eficaz das plantas.

\section{CONSIDERAÇÕES FINAIS}

A concretude do Sistema Único de Saúde baseia-se nos princípios de eqüidade, universalidade e integralidade. Para a nossa realidade específica, entretanto, a maior parte da população é, em certo sentido, expropriada de seu direito de acesso aos bens e serviços de saúde, estando esse direito embotado pela fragilidade social, cultural e intelectual dessa população.

De nosso lado, os profissionais de saúde como um todo, estão inseridos no mesmo contexto sóciocultural e político, refletindo, assim, os ideais daquele sistema. Todavia, é situado e confrontado com esse contexto, que o profissional empenhado na promoção de bem-estar dos grupos familiares, sofre com a realidade confrontada, não se submetendo à conformação e ao "status quo" (Landim, 1998).

Estimulados pelos desafios diários de demanda e complexidade dos problemas dos grupos assistidos, nós profissionais inconformados com a fome e miséria das famílias em tempos de escassez de recursos, tentamos estabelecer uma prática que foge aos rígidos padrões do modelo de saúde convencional. Para isso, passamos a valorizar as aptidões naturais das famílias para enfrentamento dos problemas visando sobreviverem às adversidades. Caracterizou-se, desta forma, uma abordagem mais realista da problemática social de saúde, ao mesmo tempo em que, como enfermeiras, nos posicionamos como mais um dos recursos de que a comunidade pode dispor para ajudar as famílias em suas escolhas.

Se assim foi, é porque entendemos que quaisquer que sejam as propostas de resolução a serem aplicadas em circunstância similar àquelas que vivenciamos, devem considerar os recursos pessoais e locais, e estarem norteadas pelo ideal de oferecer soluções práticas e viáveis à problemática identificada. Isso porque já se constatou o fracasso da rede de serviços de saúde quando, por exemplo, no âmbito hospitalar recupera uma criança do quadro de desnutrição grave e a devolve ao seu lugar de origem onde sofre privações e se expõe a inúmeros agentes agressores endêmicos na localidade em que mora. $\mathrm{Ou}$, ainda, quando ouve 0 paciente ambulatorial mas não oferece a medicação necessária para sanar seu mal, mesmo sabendo que ele não dispõe de recurso para comprá-la.

Da mesma forma, também o trabalho de acompanhamento das famílias através da visita domiciliar, seguida de orientações e instruções formais, pode não surtir o efeito desejado ou, em certos casos, pode mesmo funcionar como um agravante da situação, se não for essa visita aceita e interpretada com proveito por parte de quem a recebe. A depender, ainda, da forma como o profissional do cuidado coloca determinada problemática para a comunidade, e do quanto as famílias estão dispostas a ouvir e acatar, qualquer abordagem pode ser interpretada como uma acusação, uma intromissão e, portanto, uma violência que parece não considerar a realidade sofrida e, em certos casos, de enorme carência das famílias.

Acreditou-se para o sucesso das ações empreendidas que estimulando interações saudáveis entre membros da família e entre as famílias, centrando essas interações em assuntos de interesse imediato e concreto atingir-se-ia mais facilmente objetivos que dependessem de recursos individuais ou da própria família considerada como grupo; ao mesmo tempo que se estava habilitando às famílias ao exercício da cidadania, 0 que pode estar favorecendo a consecução dos demais objetivos de médio e longo alcance. Essa foi a idéiachave do trabalho e que o faz relevante pelo impacto que se alcançou.

Os problemas de saúde identificados puderam ser trabalhados não só por meio de estratégias de resolução que consideravam os recursos existentes e a realidade cultural e de sobrevivência local das famílias em questão, mas também buscou-se sempre ter nas organizações e entidades tomadas por referência a colaboração e parceria. Como as atividades descritas no corpo desse trabalho, outras propostas de atividades devem surgir e serem incorporadas às já existentes, justificadas pela demanda e crescente complexidade das 
problemáticas a serem trabalhadas.

ABSTRACT: It is described experience of participant observation and nursing intervention with poor families starting from the assessment and of the identification of pattern of behavior in health of 400 families. Objectives: to characterize the patterns of behavior in health; to describe nurse actions that promote natural abilities of the family in the healthcare. The sample contemplated 18 families. The determination of that sample gave him for natural process of selection, considering the people representatives of the families voluntary insertion in the promoted activities. The study was developed in two phases. The first phase was characterized by visits to the families In the second phase we promote 04 workshops that they served as space for satisfaction of needs as the ones of to produce and to create, promotion of the self-esteem, amplification of the possibilities of generation of income family. It was also initiate process of installation of a Community Medicinal Vegetable garden.

KEY WORDS: Family health; Community development; Self care.

RESUMEN: Se describe experiencia de observación participante y la intervención de enfermería con familias pobres. Se empieza por el diagnóstico y la identificación de las prácticas de conducta en salud. La población se constituye de 400 familias. Los objetivos son caracterizar las prácticas de cuidado en salud; describir acciones de la enfermera para la promoción de las habilidades naturales de la familia en el cuidado con la salud. La muestra contempló 18 familias. La determinación de esa muestra llevó en consideración la inserción en las actividades promovidas. El estudio se desarrolló en dos fases. En la primera se realizaron visitas a las familias. En la segunda nosotros promovemos 04 talleres que sirvieron como espacio para la satisfacción de necesidades psicológicas y sociales, la promoción de la autoestima, amplificación de las posibilidades de generación de ingresos para la familia. Tuvo inicio también la instalación de una plantación de hierbas medicinales.

PALABRAS CLAVE: Salud de la familia; Desarrollo de la comunidad; Autocuidado.

\section{REFERÊNCIAS BIBLIOGRÁFICAS}

1. ARAÚJ O, A. O ceará de $1 \frac{1}{2}$ salário mínimo. O POVO, Fortaleza, 20 Mar. 1999. Caderno de Economia, p. 1D.

2. BARRETO, A. Família e a favela. Universidade aberta do Nordeste. Família, Fortaleza, 1995. Família n. 7.

3. CEARÁ. Projeto Asa Branca. Relatório técnico do Grupo de trabalho. Fortaleza, 1999.

4. FRANKL, V.E. Em busca de sentido: um psicólogo no campo de concentração. Petrópolis : Vozes, 1996.

5. DEMO, P. Metodologia científica em ciências sociais. 2.ed. São Paulo : Atlas, 1992, cap. 1. p. 16-40.

6. MAMEDE, M. Família X miséria. Universidade aberta do Nordeste. Família, Fortaleza, 1995. Família n. 7.

7. MELO FILHO, J . de. Concepção Psicossomática: Visão Atual. R io de J aneiro : Tempo Brasileiro, 1994.

8. LANDIM, F.L., VARELA, Z.M.V. e CAVALCANTE, M.M.V. R ejeição da família e iatrogenia institucional: duas faces da violência. IN : VARELA, Z.M.V., SILVA, R.M.S. e BARR OSO, M.G.T. Dimensões do cotidiano: violência doméstica, saúde da mulher e desempenho no trabalho. Fortaleza : Pós-graduação/DE NF/UFC, 1998. p. 21-27.

9. LANDIM, F.L. Exercício de enfermagem e poder: profissionais entre o desconforto e o bem-estar. Fortaleza, 1998. 96p. Dissertação (Mestrado) - Universidade Federal do Ceará.

10. SAINT-ARNAUD, Y. A pessoa humana. São Paulo : Loyola, 1979.

11. SANTOS, J.B.F. dos. Desemprego, família e exclusão. Universidade aberta do Nordeste. Família, Fortaleza, 1995. Família n. 7.

12. RIBEIRO, R. Modelo industrializante na berlinda. O POVO, Fortaleza, $11 \mathrm{~J}$ ul. 1999. Caderno de Economia, p. 1E.

13. SAINT-ARNAUD, Y. A pessoa humana. São Paulo : Loyola, 1979.

14. SPRADLEY, J. The ethnographic interview. New York: Holt Reneart And Winston, 1979.

15. STÉFANO, B. Desemprego continua crescendo. O POVO, Fortaleza, 21Mai. 1999. Caderno de Economia, p. 1D.

16. VARE LA, Z.M.V. Construíndo no cotidiano da saúde: uma opção em enfermagem de saúde pública. Fortaleza, 1992. 224p. Tese (Professor Titular) - Universidade Federal do Ceará. 